\title{
HERRAMIENTAS PARA EL TURISMO RURAL COMO ESTRATEGIA DE DESARROLLO SOSTENIBLE PARA COLOMBIA, ESPECIALMENTE PARA LAS CIUDADES DE PITALITO Y SAN AGUSTÍN
}

\author{
Adelaida Cuellar Bahamón' \\ María Carolina Calderón ${ }^{2}$
}

\section{Resumen}

Una de las expresiones más poderosas de la sociedad actual es el Turismo (Pérez de las Heras, 2004). A pesar que el hecho de viajar ha existido en todas las etapas del desarrollo de la humanidad, fue solo hasta el siglo XX, durante los periodos de la postguerra, que se estableció el turismo masivo gracias a las condiciones de esta época, es decir, al aumento del tiempo libre, la disponibilidad de ingresos, el derecho a las vacaciones pagadas, las mejoras en el transporte y las comunicaciones, cuando real y rápidamente evolucionó la actividad turística (Monfor Mir, 2000).

En cuanto a Colombia, existe un tipo de turismo que se desarrolla en las áreas protegidas del Sistema de Parques Nacionales Naturales, y el presente articulo identifica las herramientas necesarias para darle el empuje decisivo al ecoturismo, de tal forma que las regiones de Pitalito y San Agustín, puedan ofrecer productos competitivos, sostenibles ambiental, social, económica y culturalmente, que generen beneficios para las comunidades locales y para su propia conservación.

Palabras clave:Sostenibilidad, Ecoturismo, Turismo, Desarrollo Sostenible 


\title{
TOOLS FOR RURAL TOURISM AS A SUSTAINABLE DEVELOPMENT STRATEGY FOR COLOMBIA ESPECIALLY FOR PITALITO AND SAN AUGUSTIN CITIES.
}

\begin{abstract}
One of the most powerful expressions of modern society is tourism (Pérez de las Heras, 2004). Despite the fact that travel has existed in all stages of the development of humanity, was only until the twentieth century during the post-war period, which was established by mass tourism and this time conditions, can be increased leisure time, available income, the right to paid holidays, improvements in transportation and communications, evolve in the course of time and now enjoy tourism (Monfor Mir, 2000).

Regarding Colombia tourism develops in the protected areas of the National Parks System, this article identifies the tools to motivate ecotourism so that the regions of Pitalito and San Agustin, can offer competitive products, environmentally sustainable, socially, economically and culturally, that generate benefits for local communities and for its own preservation.
\end{abstract}

Keywords: Sustainability, Ecotourism, Tourism, Sustainable Development.

\section{Introducción}

En el transcurso de los diferentes periodos históricos que han tenido que vivir los seres humanos, se han desarrollado ciertos eventos que como consecuencia han ayudado a dar paso al nacimiento y evolución del Turismo.

Generalmente cuando se habla de Turismo se piensa como un fenómeno perteneciente a la época moderna, como una característica de este periodo que forma parte de la vida de las personas desde que se desarrollara en las sociedades los conceptos del ocio y el consumo.

Un aspecto muy propio del turismo es ser considerado como una actividad que incita el contacto entre culturas, ayudando así, a formar un nuevo escenario que genera y fortalece las relaciones étnicas. Además es una actividad que crea en las personas un concepto serio sobre la realidad sociocultural de los pueblos que son visitados (Ministerios de Comercio Exterior y Turismo del Perú, 2004).
Hoy por hoy, el turismo es considerado más que una recompensa como un derecho de los seres humanos. El poder disfrutar del placer de un viaje y el estar lejos de los lugares frecuentados diariamente, ha pasado a formar parte de la vida de los habitantes de cualquier sociedad. Hasta tal punto, que ha dejado de verse como un premio por el trabajo realizado y se ha ido estableciendo como un hecho personal, como una experiencia autentica, a la que no se quiere renunciar, una experiencia cargada de interés y significado (Ministerios de Comercio Exterior y Turismo del Perú, 2004).

\section{Metodología}

Para la localización de los documentos bibliográficos se utilizaron varias fuentes documentales. Se realizó una búsqueda bibliográfica entre junio y septiembre de 2012, utilizando los descriptores: Sostenibilidad, Ecoturismo, Turismo, Desarrollo Sostenible. Los registros obtenidos oscilaron en- 
tre 100 y 15 registros tras la combinación de las diferentes palabras clave en el buscador Google Académico con los mismos términos.

Se seleccionaron aquellos documentos que informasen sobre los aspectos formales que debía contener una revisión la lectura crítica de documentos, las etapas de realización de una revisión bibliográfica o la elaboración de mapas mentales o mapas conceptuales.

\section{Objetivo}

Con el fin de identificar las herramientas para el turismo rural como estrategia de desarrollo sostenible para Colombia especialmente para las ciudades de Pitalito y San Agustín, se consultaron los aspectos relevantes conocidos, los desconocidos y los controvertidos sobre el Sostenibilidad, Ecoturismo, Turismo, Desarrollo Sostenible.

\section{Contenido}

El turismo en la Sociedad. Fue en el siglo XIX, cuando se disminuyeron las largas jornadas laborales y los trabajadores empezaron a tener tiempo libre durante el día y los fines de semana, además se instauraron las vacaciones pagadas para los trabajadores. Fue hasta entonces cuando las personas se plantearon la idea de visitar los parques naturales, viajar a las grandes ciudades o escaparse a las playas para desconectar de sus actividades diarias y divertirse (Cisneros, 2012).

A pesar que tradicionalmente los medios rurales generalmente han sido utilizados para la ganadería o la agricultura. En la actualidad existen una elevada cantidad de áreas protegidas, como parques, reservas indígenas, entre otras, que hoy son vistas como generadoras de desarrollo económico, gracias a actividades como el turismo de naturaleza, el ecoturismo o el turismo rural. Sin lugar a duda y como consecuencia de la agitada vida en las grandes ciudades, del abandono del campo y por consecuente la desaparición de las antiguas tradiciones. Por esta razón, los medios rurales actualmente presentan un gran encarecimiento patrimonial.

Partiendo de este punto de vista se encuentran distintos actores para quienes los medios rurales tienen diferentes funciones y significados, entre los cuales se pueden encontrar:

La administración: Quien lo entiende como un recurso eficaz para incrementar una actividad económica

Los visitantes: Que llegan en busca de tranquilidad, belleza, armonía, tradición, y están dispuestos a pagar por ello.

La población local: Quienes empezaran apreciar de una manera distinta los múltiples componentes del paisaje, como efecto del cambio de su utilización.

A pesar que lo anterior se observa como un enfrentamiento entre los actores y los diferentes usos. En general se trata de un nuevo periodo en el desarrollo del turismo.

Una de las descripciones más empleada en Europa, es aquella donde se fundamenta que el turismo rural, es aquella actividad turística realizada en el espacio rural, estructurada por una variedad de entretenimiento, una actividad que va destinada a cierta demanda estimulada por el contacto con el entorno natural y donde haya una relación directa con la comunidad local.

Algunos autores, entre ellos Santana (Santana, 2000), sustenta que la preferencia de la demanda fija la oferta de nuevos productos turísticos, los cuales pueden clasificarse en naturaleza y Patrimonio.

Según este mismo autor el turismo alternativo intenta conseguir una experiencia de lo autentico a través de la naturaleza, la cultura, la gente o una combinación de las mismas. 
Ahora bien, cuando se hace referencia en el sector turismo a inventar un producto turístico rural, se hace alusión a la disposición técnica de los recursos culturales de cierto destino, con el fin de que puedan ser visitados y disfrutados por los turistas.

Los recursos, no son más que los componentes básicos en los que se lleva a cabo una actividad turística; son aquellos encantos del lugar que logran crear u ocasionar el interés del visitante. Motivando y estableciendo el traslado a un destino concreto. Está bien decir que sin recursos no puede haber producto turístico, pero también es importante aclarar que solo los recursos turísticos no son suficientes para fabricar productos.

Dicho lo anterior es evidente la importancia que tienen los recursos, que son el encanto que posee la región, según Chías, el hombre, el legado histórico y su contorno, configuran los tres elementos base para la gestión turística. Por lo cual el producto turístico se define como el conjunto de recursos que se agrupan para el uso y goce turístico (Chias, 2004).

Ahora bien, desde el punto de vista del mercadeo turístico, un producto rural seria un recurso rural donde se pueden efectuar distintas actividades, por ejemplo ecoturismo, senderismo, cabalgatas, rafting, avistamiento de aves, entre otros. Gracias a que son actividades que contienen una entrada temporal y económica del público.

En conclusión en el turismo, en particular el turismo rural «no se venden realmente productos, sino que se venden experiencias» (Vogeler \& Hernandez, 2002). El turista siempre llega en busca de aventuras, de experiencias que le ayuden a desconectar, a relajarse, a disfrutar y a sentirse identificado con los habitantes de la zona, con sus hábitos, por lo que los visitantes compran algo más que un simple paquete turístico, compran aventuras para vivir y contar.
Como consecuencia del desarrollo de los productos turísticos tradicionales, el mercado actual está presentando nuevos estilos de turismo alternativo. De esta manera se pueden encontrar ofertas variadas en los cuales los recursos están unidos a la naturaleza, la cultura y el patrimonio y así consiguen tener una gran importancia en la experiencia del entretenimiento.

Desarrollo Sostenible. Aunque ahora se cuenta con un sistema económico cuyos principios están basados en el máximo rendimiento, el consumo, la explotación ilimitada de los recursos y el lucro. No es un secreto que es un sistema prácticamente insostenible, porque habitamos un planeta con recursos limitados, en otras palabras un planeta que no puede proporcionar eternamente los recursos necesarios para mantener el sistema económico actual.

Es en este punto donde nace el Desarrollo Sostenible. Una idea de desarrollo más positivo, que posibilite mejorar la calidad de vida, pero además que se pueda compaginar con la conservación del medio ambiente y con una explotación racionalizada del planeta.

Ahora bien, la explicación más conocida sobre el Desarrollo Sostenible se hizo en el año 1987 en la Comisión Mundial Sobre Ambiente y Desarrollo o también conocida como La Comisión Brundtland (ONU, 2010), que lo definió como:

«El desarrollo que asegura las necesidades del presente sin comprometer la capacidad de las futuras generaciones para enfrentarse a sus propias necesidades».

Según lo anterior el Desarrollo Sostenible debe:

Satisfacer las necesidades del presente, impulsando una actividad económica que proporcione los bienes necesarios a toda la población del mundo. 
Satisfacer las necesidades del futuro, minimizando las consecuencias negativas que pueda generar la actividad económica, ya sea en el consumo de recursos o en la generación de residuos, de tal manera que sea llevadero para las generaciones venideras.

Finalmente las principales características del desarrollo sostenible son: (1) Busca la forma de que la actividad económica conserve o renueve el sistema ambiental. (2) Certifica que la actividad económica mejore la calidad de todos y no solo la de unos pocos. (3) Aprovecha los recursos de manera eficiente. (4) Fomenta al máximo el reciclaje y la reutilización. (5) Apuesta por el desarrollo e implantación de tecnologías limpias. (6) Repara los ecosistemas dañados (7) Impulsa la autosuficiencia local y (8) Reconoce la importancia de la naturaleza para el bienestar de la humanidad.

El Turismo Sostenible, son todas las actividades que se caracterizan por respetar el medio natural, cultural y social, además son respetuosas con las costumbres de la comunidad, lo que da lugar a poder disfrutar de un intercambio autentico de experiencias entre residentes y visitantes, en donde la relación entre el turista y la sociedad es integra y donde los viajeros tienen una actitud realmente interactiva en su experiencia de viaje, como resultado final de estas actividades las utilidades son repartidas de manera objetiva (Ministerios de Comercio Exterior y Turismo del Perú, 2004).

Partiendo de la explicación anterior se puede afirmar que para que el turismo sea sostenible debe integrar los siguientes puntos:

El Social: Pues para ser sostenible se debe conservar la estabilidad sociocultural, proteger los valores culturales de la comunidad local, respetar su identidad cultural y su independencia para elegir su camino.
El económico: Desde este aspecto la sostenibilidad implica que la población local consiga mantener el desarrollo económico y un buen nivel de beneficios económicos a largo plazo.

El Ambiental: En este punto es imprescindible mantener la estabilidad de los sistemas físicos y biológicos. (Ver figura 1: Turismo Sostenible).

Figura 1: Turismo Sostenible

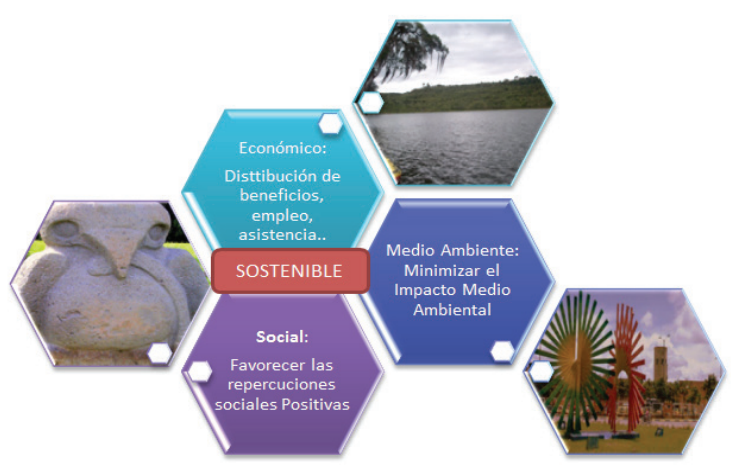

Figura 1: Fuente propia

Según la Organización Mundial del Turismo, (OMT) el turismo sostenible es: "Aquel que pretende satisfacer las necesidades de los turistas así como de los destinos turísticos, protegiendo e incrementando las oportunidades de futuro" (Pérez de las Heras, 2004). Además según la OMT, el concepto de sostenibilidad esta unido a los conceptos de calidad, equilibrio y continuidad. Por lo cual el turismo sostenible es un modelo de desarrollo económico planteado para: (1) Mejorar la calidad de vida de la población local, las personas que trabajan y viven en el destino turístico. (2) Suministrar mayor calidad de las experiencias de viaje para los visitantes. (3) Conservar la calidad del medio ambiente, pues de él dependen tanto la población local como los visitantes. (4) La obtención de mejores niveles de rentabilidad económica de la actividad turística para los residentes locales. (5) Garantizar la consecución de beneficios por parte de los empresarios turísticos. 
Resumiendo, al aplicar la sostenibilidad al Turismo lo que se pretende es fortalecer los cimientos que garanticen su duración a largo plazo, involucrando a la población local en la actividad turística y buscando la competitividad por medio de la gestión de calidad. Dicho lo anterior, la gestión turística sostenible supone certificar la biodiversidad, la autenticidad cultural, la calidad de la experiencia turística y la competitividad en el mercado.

Sin olvidar, que este desarrollo turístico sostenible debe ser compatible con el entorno sociocultural en el cual se origina. Además debe garantizar una excelente utilización de los recursos, la mitigación de los impactos y la maximización de los beneficios para la conservación y para la población local.

Herramientas para que el Turismo sea Sostenible, En la actualidad existen varias herramientas encaminadas a obtener un turismo más sostenible. Dichas herramientas pueden ser tanto para organismos gubernamentales y para empresas privadas. Y se distribuyen de la siguiente manera (EOS Marketing \& Kommunikation, 2012):

Instrumentos de Medición: Estos ayudan a establecer los niveles del turismo y el impacto que este genera. Entre ellos se pueden encontrar: La medición anual de indicadores de turismo, los planes de consumo energético, etc.

Instrumentos de Control por parte de las Organizaciones Gubernamentales: Dichos instrumentos van dirigidos a instaurar un marco legal y un control estricto sobre el desarrollo y el crecimiento de la actividad turística.

Instrumentos Económicos: Estos influyen en el comportamiento del sector a través de medios económicos y mandando señales al mercado. Por ejemplo: A través de tasas o impuestos para las actividades No sostenibles, o por el contrario a través de estímulos económicos que apoyen a las empresas a efectuar sus actividades de una manera más sostenible.

Instrumentos Voluntarios: Estos instrumentos ayudan a formar un escenario o unos procesos que estimulan a la unión voluntaria a una orientación y a unas prácticas sostenibles. Pueden ser: los códigos de conducta, los certificados de sostenibilidad, los premios, etc.

Instrumentos de apoyo: Con ellos se busca que los gobiernos puedan apoyar a las empresas o a los turistas a que realicen sus actividades de una manera más sostenible. Por ejemplo: Por medio de los cursos de formación, campañas de marketing destinadas a influir en el comportamiento de los turistas, la buena administración del agua, energía o recursos, etc.

En general lo que se necesita para conseguir que el Turismo sea sostenible es hacer un compromiso con la sostenibilidad en sus acciones. De esta manera independientemente de los instrumentos que se apliquen se contribuirá a tener un turismo más sostenible.

Turismo Rural, Es conocido como el espacio donde se llevan a cabo las actividades, es decir abarca puntos como: el hospedaje rural, la elaboración de artesanías y las actividades en áreas naturales (Cánoves Valiente, Jiménez Herrera, \& Villarino Pérez, 2005).

La OMT lo define como «El conjunto de actividades que se desarrollan en el entorno rural y pueden constituirse para los habitantes del medio en una fuente de ingresos complementarios a los tradicionalmente dependientes del sector primario convirtiéndose en un rubro productivo más de la empresa agropecuaria» (Roman \& Ciccionella, 2009).

Las actividades del turismo rural suelen caracterizarse por: ser locales, incluir el contacto personalizado y compartir experiencias con los 
habitantes del medio rural. También supone una práctica formativa e interactiva, en donde los grupos rurales tienen un papel muy importante en la prestación de servicios. Dichas actividades pueden ser el ecoturismo, senderismo, agroturismo, entre otras (Montijn \& Carré, 2005).

Tanto para países desarrollados como para países en vía de desarrollo, el turismo rural se ha transformado en una opción para la diversificación económica y un elemento eficiente en el renacimiento de territorios que se hallaban económicamente deprimidos. Por tanto, a través de una correcta planificación y dirección el turismo rural ayuda a:

Variar la producción rural.

Generar empleo, creando nuevas oportunidades laborales para los jóvenes y las mujeres.

Promueve la vida en el medio rural, de esta manera ayuda a disminuir el abandono del campo y la división de las familias rurales.

Aumenta el valor del patrimonio cultural y natural, produciendo así fondos para su propia conservación.

Crea valor agregado en la producción primaria, lo que sirve para lograr una óptima distribución y comercialización de estos productos, además de aumentar los ingresos domésticos.

Fomenta nuevas inversiones con las que se benefician tanto la población local como los turistas y visitantes.

Añade valor agregado y amplía las ofertas turísticas.

Revalorizar a las sociedades que habitan los medios rurales y fortalece su cultura.
Ofrece un alza en la calidad de vida de las comunidades locales, gracias a la mejora en la infraestructura de acceso, comunicaciones y otros servicios sociales.

El Sistema Turístico, De acuerdo a lo descrito por el Instituto Mexicano de Investigaciones Turísticas un sistema turístico se conoce como un "conjunto definible de relaciones, servicios e instalaciones que interactúan cooperativamente para realizar las funciones que promueven, favorecen y mantienen la afluencia y estancia temporal de los visitantes».

En estos sistemas se encuentran los siguientes elementos (Estrada Solozabal, 2009):

Los turistas: Son la figura primordial y el objetivo principal de cualquier sistema. Se pueden desempeñar como consumidores, clientes y examinadores del turismo.

Elementos geográficos: Se encuentran 3 entornos que son: (1) Región generadora de viajeros, (2) Región de destino turístico y (3) Región de tránsito en ruta.

La industria Turística: Esta estimada como el espacio donde se implican los negocios y las empresas. Un punto importante es que según el modelo y con el fin de crear una red de comunicación y transacciones, cada uno de los elementos identificados anteriormente se relaciona de manera diferente con los demás. De esta manera logra producir una cadena de impactos en los entornos geográficos identificados.

Para las regiones interesadas en implementar el turismo sostenible es muy importante tener conocimiento de estas interrelaciones pues así se tendrán las herramientas necesarias para formar un proceso de planificación más adecuado. (Ver figura 2: Sistema Turístico) 
Figura 2: Sistema Turístico

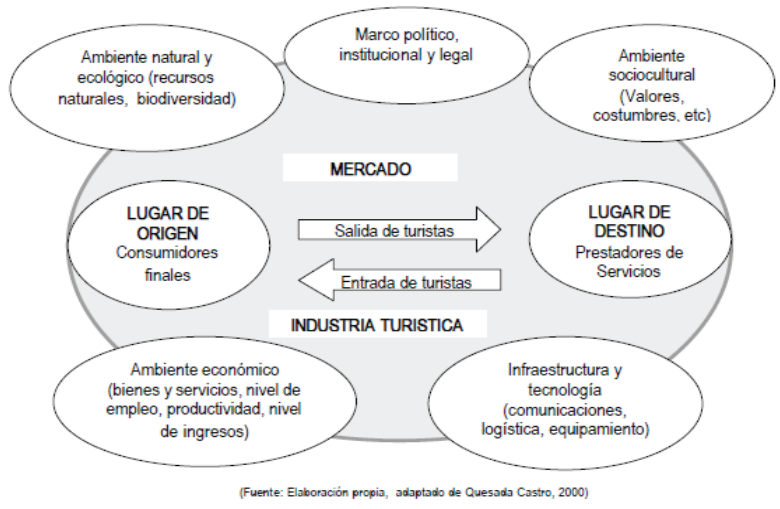

Fuente: (Montijn \& Carré, 2005).

Megatendencias Turísticas, Globalización y Localización. De acuerdo al estudio sobre ecoturismo en el Corredor Verde llevado a cabo al nordeste de Argentina, frontera con Brasil y Paraguay (Montijn \& Carré, 2005), las principales son:

1. La tecnología como componente supremo ya sea para influir en la elección del destino o su distribución.

2. Se aplicaran medidas que harán más fácil y rápido el proceso de viaje. En otras palabra el Viaje Rápido.

3. A través de la utilización de las tecnologías como el Internet los turistas podrán tener acceso de manera independiente a las ofertas lanzadas a sitios web por los intermediarios. Ofertas como: Billetes aéreos de última hora a precios más bajos, habitaciones con descuentos, etc.

4. La división de los gustos turísticos, pues habrá turistas que prefieran la comodidad y otros que sean apasionados por las aventuras.

5. Fortalecimiento de los destinos turísticos insólitos.

6. Consolidación en la oferta de productos, que asocien una o dos combinaciones de las tres E: Entretenimiento, Excitación y Educación.

7. Los destinos turísticos se centraran en atraer el mercado a través del refuerzo de la Imagen como un requisito indispensable para mostrar su diversificación.

8. El mercado mundial tiene como objetivo principal seducir a los turistas asiáticos.

9. Según la OMT para el 2020 se confía que China será el principal destino turístico. Con una representación del mercado del 8.3\%.

10. Se hará cada vez más evidente el progresivo impacto de las campañas dirigidas por los consumidores para conseguir el desarrollo turístico sostenible y el comercio justo en el turismo mundial.

La Situación en Colombia, Colombia es un país muy rico en cultura e historia, además de ser muy privilegiado, pues gracias a su ubicación geografía, se encuentra bañado por dos mares y en su territorio se puede disfrutar de la mayor biodiversidad del mundo por kilometro cuadrado. Por lo cual el país cuenta con un potencial único e inmenso para explotar cualquier modalidad del turismo, específicamente el Turismo Rural, una actividad que ha aumentado su demanda en los últimos años, especialmente en los países más desarrollados (Proexport, 2010).

En una entrevista efectuada a la presidenta de Proexport, María Claudia Lacouture, durante la conferencia Suramericana de Inversiones y Turismo Sahic 2010, declaro que: La diversidad natural de Colombia y la visión estratégica del sector consolidan al país como un multidestino turístico de talla internacional y lo que han permitido ingresar a las listas de los mejores del mundo. Por lo que el número de visitantes extranjeros se triplico en los últimos seis 
años, pues durante el 2009 mientras el turismo mundial descendía un $4 \%$, en Colombia tuvo un aumento del 10,7\% (Lacouture, 2010).

Asimismo resaltó que el turismo se ha convertido en uno de los principales motores del desarrollo del país y que esto ha sido posible gracias a los avances económicos y de seguridad que se han producido en la nación.

Ecoturismo Sostenible en los Municipios de Pitalito y San Agustín

Para poder establecer el ecoturismo como estrategia de desarrollo sostenible en las ciudades de Pitalito y San Agustín, es preciso tener en cuenta las leyes y los reglamentos pertinentes que guían esta actividad, ya sean leyes nacionales como regionales de áreas protegidas y de la actividad turística. En seguida se mostrara una síntesis de las que se estiman como grandes leyes que limitan, conducen o sencillamente mencionan el desarrollo del ecoturismo dentro del entorno de su utilización.

La Agenda 21, debe considerar estos tres temas: la sostenibilidad ambiental, la justicia social y el equilibrio económico, y cada localidad puede implementar su propia Agenda 21, con la condición de conseguir la colaboración de las fuerzas sociales que la integran (Ministerio de Ambiente y Desarrollo Sostenible, 2012).

Declaración de Berlín: acerca de «Diversidad biológica y Turismo Sostenible», El tema principal de esta Declaración fue La relación entre la diversidad biológica y el turismo. Donde lograron integrar y hacer hincapié a elementos ambientales y sociales. El punto más importante hace referencia a la repartición entre la población y las economías locales de la explotación sostenible de la biodiversidad en las actividades turísticas (Ministerio de Ambiente y Desarrollo Sostenible, 1997).
Declaración de Quebec, En esta declaración principalmente se trató el tema del Ecoturismo, continuando con un punto de vista limitado de la sostenibilidad y ratificando que el ecoturismo es una manera de conseguir recursos para la conservación y la gestión de las zonas protegidas de exuberante biodiversidad y cultura, además de la importancia de su conservación para las generaciones venideras (Naciones unidas Centro de Información para México, 2002).

Normatividad de Apoyo para el Ecoturismo, En relación con los aspectos normativos de Colombia. En el país se ha estado trabajando en el desarrollo de una legislación de gran relevancia para la conservación de los recursos naturales, entre ella sobresalen:

La Constitución Política, La constitución política de 1991, además de garantizar el derecho que todas las personas tienen a gozar de un ambiente sano, en su artículo 79. De la misma manera incluye el concepto de desarrollo sostenible al decretar la obligación del Estado de «planificar el manejo y aprovechamiento de los recursos naturales» y prevenir los factores que ocasiones riesgos a su conservación o conduzcan a su deterioro tal y como se establece en el artículo 80. Destacando que la conservación de la biodiversidad tiene como objetivo garantizar la calidad de vida de todos los ciudadanos (Constitución Política de Colombia, 1991).

Ley 99 de 1993, Esta ley establece en su artículo 1, num2 que «La biodiversidad del país, por ser patrimonio nacional y de interés de la humanidad, deberá ser protegida prioritariamente y aprovechada en forma sostenible». Así mismo en su artículo 3 acuerda: «se entiende por desarrollo sostenible el que conduzca al crecimiento económico, a la elevación de la calidad de vida y al bienestar social, sin agotar la base de recursos naturales renovables en que se sustenta, ni deteriorar el media ambiente o el derecho de las 
generaciones futuras a utilizarlo para la satisfacción de sus propias necesidades» (Diario Oficial de Colombia , 1993).

Ley 300 de 1996: Ley General del Turismo, Dicha ley en su artículo 1 admite que el turismo «Es una industria esencial para el desarrollo del país y en especial de las diferentes entidades territoriales, regiones, provincias y que cumple una función social. Por tanto el Estado le dará especial protección en razón de su importancia para el desarrollo nacional» (Ley General de Turismo, 1996).

Al mismo tiempo propone que la actividad turística deberá participar en un sector oficial, un sector mixto y un sector privado. Compuestos de la siguiente manera:

Sector oficial: Compuesto por el Ministerio de Comercio, Industria y Turismo, sus entidades adscritas y vinculadas, las entidades territoriales y Prosocial, así como las demás entidades públicas.

Sector Mixto: Consejo Superior del Turismo, el consejo de facilitación turística y el comité de capacitación turística.

Sector privado: prestadores de servicios turísticos, sus asociaciones gremiales y las formas asociativas de promoción y desarrollo turístico existentes y las que se creen para tal fin.

Política para el Desarrollo del Ecoturismo, En general esta política determina las estrategias necesarias para la conformación interinstitucional del Ecoturismo.

Fue creada con el fin de impulsar, evaluar y articular la implementación de planes, programas y proyectos para fortalecer el ecoturismo en el país, desarrollados en el marco de la política para el desarrollo del ecoturismo en Colombia y ser órgano de consulta y definición de lineamientos para los asuntos que el sector estime oportuno someter a su consideración. (Política para el Desarrollo del Ecoturismo, 2003).

Plan de Ordenamiento Territorial Municipio Pitalito, Según el Plan de Ordenamiento Territorial (Alcaldía Municipal de Pitalito, 2011), Pitalito se ha convertido en la ciudad más importante del sur colombiano, imprescindible para el desarrollo integral de la región, influyente en el sur del Departamento del Huila, y en los Departamentos de Putumayo, Caquetá y Cauca, por tal motivo se conoce como ciudad región del sur colombiano.

El Municipio está ubicado a 188 kilómetros de la capital huilense, a 1.300 metros sobre el nivel del mar, con una temperatura promedio entre 18 y $21^{\circ} \mathrm{C}$ y con una extensión total de 591 kilómetros cuadrados.

En lo que respecta a su actividad económica, se ha determinado que el $11.4 \%$ se dedican a la industria, el $52.7 \%$ al comercio, el $27.2 \%$ a servicios y el $8.8 \%$ a de otra actividad (Ver figura 3: Establecimientos según actividad económica).

Figura 3. Establecimientos según actividad económica

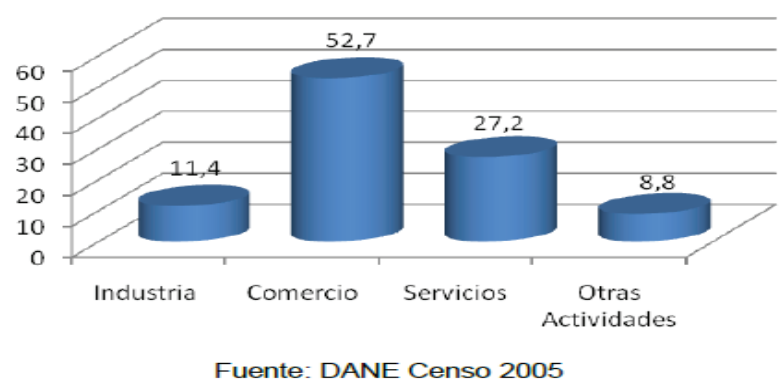

Vale la pena señalar que más allá de las cifras y de las estadísticas, el Municipio cuenta además con un excelente capital: humano, natural, geográfico, social e institucional para dar solución a sus problemas, enfrentar sus retos y conseguir su visión de capital regional. 
Plan de Ordenamiento Municipio de San Agustín, «San Agustín compone un territorio privilegiado, tanto por la naturaleza como por la historia, es una Bioregión del Macizo Colombiano, rio Magdalena, arqueología y belleza sin par de valles, montañas y mesetas. Lugar considerado por los estudiosos como especial y único, localizado al sur del departamento del Huila, en las estribaciones de las cordilleras Central y Oriental» (Alcaldía Municipal de Pitalito, 2011). Presenta una extensión territorial de 1.359 Km2, con una altura sobre el nivel del mar de 1695 metros; con una temperatura media de $18^{\circ} \mathrm{C}$. Constituido por 85 veredas y 16 barrios, con una población de 33.736 habitantes.

La inestable situación económica, cuyas repercusiones se reflejan en los problemas sociales, deja en evidencia como San Agustín se encuentra aún distante de mejorar el Índice de Calidad de Vida, pues su déficit se encuentra arriba del $50 \%$, haciendo urgente la intervención del ente municipal, a fin de contrarrestar dichas falencias (Alcaldía Municipal de San Agustín, 2011).

El turismo y la cultura representan el más grande potencial del municipio para mejorar en su desarrollo económico y consolidar la identidad cultural. Es bien sabido que San Agustín no ha explotado todo el potencial de sus recursos turísticos, por lo que está en proceso de progresar en ese sentido.

Ecoturismo Sostenible en los Municipios de Pitalito y San Agustín, Para poder establecer el ecoturismo como estrategia de desarrollo sostenible en las ciudades de Pitalito y San Agustín, es preciso tener en cuenta las leyes y los reglamentos pertinentes que guían esta actividad, ya sean leyes nacionales como regionales de áreas protegidas y de la actividad turística. En seguida se mostrara una síntesis de las que se estiman como grandes leyes que limitan, conducen o sencillamente mencionan el desarrollo del ecoturismo dentro del entorno de su utilización.
Plan de Ordenamiento Municipal-Pitalito, Este documento destaca que la Administración Municipal será guiada bajo los principios de sustentabilidad ambiental, de tal manera se podrá garantizar a las futuras generaciones el derecho a gozar de un ambiente sano, así como unos recursos naturales conformes a sus necesidades, para lo que es conveniente crear una cultura y conciencia ambiental, así se lograra proteger las fuentes de agua y les especies de fauna y flora de la región. Dentro de las estrategias establecidas para alcanzar los objetivos de sostenibilidad del Municipio, se encuentra una que se denominada: Ambiente, productividad y competitividad para mejorar la calidad de vida, cuyo objetivo sectorial es «fortalecer y apoyar los sectores económicos del municipio, optimizando la productividad y competitividad de manera sostenible mediante la articulación e implementación de estrategias, proyectos y alianzas entre el sector público y privado con el fin de mejorar la calidad de vida de la población laboyana y posicionando a Pitalito como polo de desarrollo de la Región Surcolombiana».

Así mismo, se encuentra un subprograma de Desarrollo Turístico, con e que se busca «potenciar la vocación turística de Pitalito haciendo un uso estratégico de sus riquezas naturales, arquitectónica y culturales». Para lo cual se han definido los siguientes proyectos: (1) Formulación e implementación del Plan estratégico Turístico, (2) Gestión para la cofinanciación de Proyectos Turísticos y (3) Diseño y operatividad de los productos turísticos del Parque de Vaguará y la Laguna de Guatipán. Con ello se pretenden diseñar un producto turístico en torno al Café, el Agroturismo y el Turismo de Naturaleza.

Plan de Ordenamiento Municipal-San Agustín, Este documento desde el inicio resalta que en el Municipio de San Agustín el turismo y la cultura son sus más grandes potenciales para progresar en su desarrollo económico y de esta manera consolidar la identidad cultural. 
Igualmente confirma que San Agustín no ha aprovechado todo el potencial de sus recursos turísticos, por lo que debe mejorar en ese sentido, al igual que en lo concerniente con los recursos naturales y paisajísticos.

Actualmente cerca del $10 \%$ de la población se dedica al turismo, aunque, la demanda del mercado turístico por el ecoturismo, el agroturismo, y el turismo de aventura, sumado al histórico patrimonio arqueológico y cultural, muestran una tendencia clara para alcanzar el tren del desarrollo gracias a este potencial.

La construcción de estrategias de desarrollo turístico con base en una cultura de valores autentica es una herramienta, aunada a la Cooperación, la seguridad, la organización interna, la generación de un producto turístico de calidad y la promoción y comercialización, integrando el sector agropecuario y la belleza paisajística a la producción turística», lo anterior se debe a que dichos elementos son los que originan su desarrollo.

En lo relacionado con la colaboración, los proyectos turísticos tienen que ser básicamente de base territorial, y así poder conseguir los recursos destinados a generar proyectos que favorezcan el posicionamiento estratégico de un producto autóctono en los mercados turísticos tanto del país como del exterior.

Debido a las características de San Agustín, su distancia de los centros urbanos y su ubicación en el Macizo Colombiano, lo convierte en un territorio topográficamente complejo, por lo que el tema de la seguridad es elemental ya sea para ofrecer protección a los visitantes o para llevar un registro efectivo de las actividades de los prestadores de servicios turísticos.

En cuanto a lo vinculado con la Generación de Productos Turísticos, los proyectos turísticos deben convertirse en productos turísticos con- cretos, en otras palabras, en una oferta asequible y completamente viable a los turistas.

En general el Plan de Ordenamiento Municipal, realza que es necesaria la reformación social, la identificación de la cultura agustiniana, como centro de «entendimiento y de cambio en el servicio al cliente, en la identidad de su futuro en la producción turística, lo que hace necesario la creación de núcleo emprendedor, de forma que en ella exista un número importante de empresarios y servicios turísticos de calidad que garanticen que si haya un avance efectivo y sólido del sector turístico en el Huila».

\section{Conclusiones}

Si bien es verdad que la costumbre de disfrutar de las vacaciones en los medios rurales la hemos heredado de nuestros antepasados, también es verdad que la manera como hoy se conoce, al igual que el entorno en donde se desenvuelve el turismo rural lo hace ser una actividad que ocasiona grandes cambios en el uso de este medio.

Así mismo, en las sociedades actuales el turismo se utiliza como una manera de fortalecer la interacción cultural de los pueblos, llegando a ser en la mayoría de las ocasiones la causa que incita a los individuos a viajar; pues el solo hecho de estar en contacto con una cultura diferente se convierte en una experiencia única que estimula la creatividad de las personas y como consecuencia se establece en una condición necesaria para la realización de las aptitudes del hombre.

Durante el desarrollo de este documento se ha mencionado en algunos párrafos, la trascendencia económica que tiene el turismo a nivel mundial, siendo esta la razón por la que el gobierno adquiriere el compromiso de planear y financiar los destinos turísticos. Aunque es una realidad que el turismo es un componente importante para el desarrollo regional en muchos lugares del 
mundo, no se puede pasar por alto los impactos perjudiciales que ha ocasionado y la exclusión a la que se ha sometido a la población local.

Dejando de forma manifiesta, que una de las características más destacadas de la actividad turística son los beneficios económicos que esta genera, ignorando en muchas ocasiones que los costos sociales y ecológicos causados por esta práctica son más elevados e irreversibles que los beneficios económicos que se pueden obtener (Bringas, 1997).

Sin embargo, cuando se trata del Ecoturismo específicamente, es evidente que esta actividad no puede producir las mismas consecuencias negativas que el turismo de masas ocasiona. Pero, lastimosamente en el caso de países en vía de desarrollo como Colombia, el utilizar la partícula «eco» no garantiza la sostenibilidad y mucho menos el respeto por la naturaleza, al contrario esta palabra se puede utilizar como gancho para atraer las inversiones externas. Por lo que es necesario establecer un compromiso con la sostenibilidad y sus operaciones, para favorecer la formación e instauración de un turismo más sostenible en el país (Bringas, 2000).

En general, las predicciones sobre el desempeño del turismo mundial indican un gran crecimiento en los viajes a la naturaleza, en especial se destaca el interés de los países desarrollados por los que se encuentran en vías de desarrollo. Siguiendo por esta línea, nuestro país y especialmente las ciudades de Pitalito y San Agustín, pueden aprovechar su gran potencial turístico y ver en el ecoturismo una oportunidad para reinventar el turismo, desarrollando nuevas maneras para emplear el tiempo libre, actividades que produzcan beneficios personales y económicos, al mismo tiempo que se conservan los recursos naturales y culturales.
En suma a lo anterior, se encuentra una dificultan existente al momento de definir conceptualmente y establecer las diferencias entre los variados tipos de turismo que se apoyan en los medios naturales, por lo que en ocasiones se pueden encontrar tour operadores a nivel mundial que encuentran la oportunidad y utilizan la confusión para disfrazar estos productos como turismo verde y poderlos promocionar de forma masiva.

En consecuencia a lo anterior se puede pensar que no todas las formas de turismo alternativo basado en los medios naturales, son sostenibles ecológicamente, ni mantienen los recursos económicos en las comunidades receptoras. Pues si observamos con detenimiento la situación del turismo en Colombia es muy fácil encontrar casos donde se observa una gran tendencia a masificar los destinos, sin tener en cuenta los impactos negativos que esta actividad genera en el entorno. Aun así se pretende establecer el turismo rural en zonas que pueden deteriorarse con mucha facilidad, sin la garantía de un control en el flujo de visitantes y sin establecer que los ingresos ocasionados por esta actividad permanecerán en la localidad. Pues el mejor escenario sería que la repartición de los ingresos fuera de manera totalmente opuesta a lo que ocurre actualmente, en otras palabras, que una parte considerable de estos beneficios se quede en las comunidades locales.

Por último, es evidente que el Ecoturismo es una actividad con un potencial extraordinario para Colombia, en especial para las ciudades de Pitalito y San Agustín. Pues es una manera factible de variar la oferta turística, mientras se aumentan las ventajas económicas. No obstante, si se quiere que esta actividad además de cumplir con los objetivos económicos, también sea ecológica, social y culturalmente sostenible, es necesario contar con la implicación de la comunidad local para la conservación y preservación de estos lugares. 


\section{Referencias}

Alcaldía Municipal de Pitalito. (2011). Plan de Ordenamiento Municipal 2011-2014. Pitalito, Huila.

Alcaldía Municipal de San Agustín. (2011). Plan de Ordenamiento Municipal 2011-2014. San Agustín, Huila.

Baquerizo, C. (2008). La Crisis Financiera y su Consecuencia. Disponible en: http://www.desdemitrinchera. com/2008/10/31/la-crisis-financiera-y-sus-consecuencias/

Bringas, N. (1997). Las Dos Caras del Ecoturismo: beneficios económicos contra costos sociales, culturales y ecológicos. Miradas sobre America Latina. 7 (18)-:, 89-116.

Bringas, N. (2000). El Ecoturismo: ¿Una Nueva Modalidad del Turismo de Masas?. Economía, Sociedad y Territorio. El Colegio Mexiquense, A.C. Toluca, México., Enero-Junio, Vol. II, núm. 7.

Cánoves Valiente, G., Jiménez Herrera, L., \& Villarino Pérez, M. (2005). Turismo Rural en España: Paisajes y Usuarios, Nuevos usos y Nuevas visiones. Cuadernos de Turismo.

Chias, J. (2004). Chías, J. (2004). El negocio de la Felicidad. Desarrollo de Marketing Turístico de Países, Regiones, Ciudades y Lugares. Madrid.: Prentice Hall.

Cisneros M., L. (22 de 02 de 2012). Antecedentes Históricos del Turismo. Disponible en: http://ebookbrowsee.net/ antecedentes-historico-del-turismo-pdf-d312684879: http://ebookbrowsee.net/antecedentes-historico-del-turismo-pdf-d312684879

Constitución Política de Colombia. (1991). Constitución Política de Colombia. Obtenido de http://cms-static.colombiaaprende.edu.co/cache/binaries/articles-186370_ constitucion_politica.pdf?binary_rand $=1416$

Diario Oficial de Colombia. (Diciembre de 1993). Ministerio de Ambiente y Desarrollo Sostenible. Disponible en: http://www.minambiente.gov.co/documentos/normativa/ ley/ley_0099_221293.pdf

EOS Marketing \& Kommunikation. (15 de Agosto de 2012). EOS Sustainable Tourism Developmen - Stuttgart, Germany. Disponible en: http://www.eos-std.de/turismo_ sostenible.html

Estrada Solozabal, C. (30 de octubre de 2009). El enfque sistémico-hermenéutico una propuesta de acción comunicativa para los soportes de esparcimiento y recreación de la Delegación Gustavo A. Madero. México, México D.F., México .
George, S. (2001). Informe lugano: como preservar el capitalismo en el siglo XXI. Madrid: Icaria.

Lacouture, M. C. (28 de septiembre de 2010). Conferencia Suramericana de Inversiones y turismo Sahic. (P. http://www.youtube.com/watch?v=MIEO4dcFx2I, Entrevistador)

Ley General de Turismo. (1996). Ley General de Turismo. Obtenido de http://www.redturs.org/inicio/docu/colombia/gobierno/colgn2.pdf

Ministerio de Ambiente y Desarrollo Sostenible. (1997). Declaración de Berlín «Conferencia Internacional de Ministros Ambiente sobre Biodiversidad y Turismo». Berlin.

Ministerio de Ambiente y Desarrollo Sostenible. (2012). Colombia, 20 años siguiendo la Agenda 21. Bogotá: Ministerio de Ambiente y Desarrollo Sostenible.

Ministerios de Comercio Exterior y Turismo del Perú. (2004). http://www.mincetur.gob.pe/newweb/. Obtenido de http://www.mincetur.gob.pe/TURISMO/Producto_turistico/Fit/fit/Guias/Amazonas.pdf: http://www.mincetur. gob.pe/TURISMO/Producto_turistico/Fit/fit/Guias/Amazonas.pdf

Monfor Mir, V. M. (2000). La Politica Turistica: Una aproximación. Cuadernos de Turismo, 7-27.

Montijn, L. V., \& Carré, M. (Noviembre de 2005). Agencia Española de Cooperación Internacional para el Desarrollo. Obtenido de Estudio sobre Ecoturismo: http:// www.aecid.org.ar/administrador/publicaciones/TDR3_ ECOTURISMO_Parte1.pdf

Mustelier, D. L. (2008). Antecedentes Historicos del Turismo. 1-20.

Naciones unidas - Centro de Información para México, C. y. (22 de mayo de 2002). Declaración de Quebec sobre el Ecoturismo. Obtenido de Año Internacional del Ecoturismo 2002: http://www.cinu.org.mx/eventos/turismo2002/doctos/dec_quebec.htm

ONU. (Septiembre de 2010). La ONU pone en marcha Informe Brundtland I/ sobre Desarrollo Sostenible. Obtenido de http://www.cecodes.org.co/index.php/boletinseptiembre-2010/832.html: http://www.cecodes.org.co/ index.php/boletin-septiembre-2010/832.html

Pérez de las Heras, M. (2004). Manual del Turismo Sostenible. Como conseguir un turismo social, económico y ambientalmetne responsable. Barcelona: Ediciones Mundi-prensa. 
Política para el Desarrollo del Ecoturismo. (20 de Junio de 2003 ). Política para el Desarrollo del Ecoturismo. Obtenido de http://www.parquesnacionales.gov.co/PNN/ portel/libreria/pdf/PolticaNacionaldeEcoturismo.pdf

Proexport. (2010). Turismo verde: sostenibilidad en Colombia. Obtenido de http://www.colombia.travel/es/turistainternacional/actividad/turismo-verde: http://www.colombia.travel/es/turista-internacional/actividad/turismo-verde

Roman, M. F., \& Ciccionella, M. (2009). Turismo Rural en Argentina, Concepto,s ituación y perspectiva. Buenos Aires: IICA.
Santana, A. (2000). O rural como produto turístico: algo de novo brilha sob o sol? Brasil: Editorial Papirus.

Vogeler, C. y. (2002). El Mercado Ecoturistico: Estructura, Operaciones y Procesos de Produccion. Madrid, España: Centro de Estudios Ramon Areces.

Vogeler, C., \& Hernandez, E. (2002). El Mercado Ecoturistico: Estructura, Operaciones y Procesos de Produccion. Centro de Estudios Ramon Areces. 